\title{
HUBUNGAN KEHAMILAN POSTTERM, PARTUS LAMA DAN AIR KETUBAN BERCAMPUR MEKONIUM DENGAN KEJADIAN ASFIKSIA NEONATORUM
}

\author{
Herawati $^{1}$, Rizki Amalia ${ }^{2}$, Dewi Aprilia Sari ${ }^{3}$ \\ Program Studi Diploma IV Kebidanan Universitas Kader Bangsa Palembang \\ Jl. Mayjend H.M. Ryacudu No. 88 Palembang Sumatera Selatan, Indonesia \\ Email : sari.dewihidayat@gmail.com
}

\begin{abstract}
Abstrak
Asfiksia neonatorum adalah keadaan dimana bayi baru lahir (BBL) tidak segera dapat bernafas secara spontan dan teratur. Berdasarkan data yang diperoleh dari Rumah Sakit Pusri Palembang tahun 2018 ada 116 bayi (7,09\%) yang mengalami asfiksia neonatorum. Tujuan penelitian ini diketahui hubungan kehamilan postterm, partus lama dan air ketuban bercampur mekonium secara simultan maupun parsial dengan kejadian asfiksia neonatorum di Rumah Sakit Pusri Palembang tahun 2018. Metode yang digunakan dalam penelitian ini adalah survey analitik dengan pendekatan cross sectional. Populasi dalam penelitian ini adalah semua bayi baru lahir di Rumah Sakit Pusri Palembang tahun 2018 yang tercatat di rekam medik berjumlah 1635 orang, dengan total sampel 94 responden yang diambil dengan teknik systematic random sampling dan dianalisis secara univariat dan bivariat dengan uji statistik chi square. Hasil analisis univariat menunjukkan dari 94 responden, 25 responden (26,6\%) mengalami asfiksia neonatorum. Dari hasil uji chi square menunjukkan ada hubungan yang bermakna antara kehamilan postterm dengan kejadian asfiksia neonatorum dengan $\rho$ value $=0,002<\alpha=0,05$, ada hubungan yang bermakna antara partus lama dengan kejadian asfiksia neonatorum dengan $\rho$ value $=$ $0,001<\alpha=0,05$, dan ada hubungan yang bermakna antara bayi yang mengalami air ketuban bercampur mekonium dengan kejadian asfiksia neonatorum diperoleh $\rho$ value $=0,002<\alpha=0,05$. Hasil penelitian ini diharapkan dapat menjadi gambaran bagi petugas kesehatan dan penentu kebijakan sebagai bahan pertimbangan, informasi dan pengambilan keputusan untuk penatalaksanaan bayi baru lahir dengan asfiksia neonatorum.
\end{abstract}

Kata kunci : Asfiksia Neonatorum, Kehamilan Postterm, Partus Lama, Air Ketuban Bercampur Mekonium

\begin{abstract}
Neonatal asphyxia is a condition in which a newborn (BBL) cannot immediately breathe spontaneously and regularly. Based on the data obtained from the hospital in 2018, there were 116 babies (7.09\%) who experienced neonatal asphyxia. This study aimed to determine the correlation between postterm pregnancy, prolonged labor, and amniotic fluid mixed with meconium simultaneously or partially with the incidence of neonatal asphyxia in Pusri Hospital Palembang in 2018. The method used in this study was analytical survey with a cross sectional approach. The population in this study was all newborns (1, 635 people) recorded in the medical record of the hospital $m$ 2018, with a total sample of 94 respondents taken by systematic random sampling and analyzed using univariate and bivariate analyses with chi-square statistical test. The result of univariate analysis showed that 25 respondents (26.6\%) out of 94 respondents experienced neonatal asphyxia. The chi-square test results showed that there was a significant correlation between postterm pregnancy and the incidence of neonatal asphyxia with $p$ value $=0.002<a=0.05$, there was a significant correlation between prolonged labor with neonatal asphyxia with $p$ value $=0.001<a=0.05$, and there was a significant correlation between amniotic fluid mixed with meconium with the incidence of neonatal asphyxia with $p$ value $=0.002<a=$ 0.05. the result of this study is expected to be as a reference for health workers and policy makers in making decision in the management of newborn with neonatal asphyxia.
\end{abstract}

Keywords : Neonatal Asphyxia, Postterm Pregnancy, Prolonged Labor, Amniotic Fluid Mixed with Meconium 


\section{PENDAHULUAN}

Asfiksia neonatorum merupakan masalah yang menyebabkan tingginya tingkat morbiditas dan mortalitas pada neonatus, diperkirakan insidensinya sekitar 4-9 juta kasus dari 130 juta kelahiran. Angka kematian bayi di Indonesia saat ini adalah sebesar 34 per 1000 kelahiran hidup dengan sepertiga dari kematian bayi terjadi pada bulan pertama setelah kelahiran dan $80 \%$ di antaranya terjadi pada minggu pertama dengan penyebab utama kematian adalah gangguan pernapasan akut dan komplikasi perinatal (Saifuddun, 2014).

Untuk menurunkan angka kematian bayi baru lahir karena asfiksia, persalinan harus dilakukan oleh tenaga kesehatan yang memiliki kemampuan dan keterampilan manajemen asfiksia pada bayi baru lahir, kemampuan dan keterampilan ini digunakan setiap kali menolong persalinan (JNPKKR,2015).

Angka Kematian Bayi (AKB) menjadi indikator kesehatan pertama dalam menentukan derajat kesehatan anak karena merupakan cerminan dari status kesehatan anak pada saat ini serta merupakan salah satu indikator keberhasilan pembangunan suatu bangsa. Pada tahun 2017 angka kematian bayi yang disebabkan oleh asfiksia di usia 0 - 27 hari terbanyak terdapat di India sebanyak 114.306 bayi, diikuti oleh Nigeria sebanyak 76.154 bayi, kemudian Pakistan sebanyak 53.110 bayi, sedangkan di Indonesia sebanyak 13.843 bayi (WHO, 2017).

Setiap tahunnya sekitar 3\% (3,6 juta) dari 120 juta bayi lahir mengalami asfiksia, hampir 1 juta bayi ini kemudian meninggal. Di Indonesia dari seluruh kematian bayi, sebanyak 38\% meninggal pada masa bayi baru lahir. Kematian bayi baru lahir ini disebabkan oleh asfiksia sebanyak 36,9\% (Kementerian Kesehatan RI, 2012).

$\begin{array}{cccr}\text { Hasil } & \text { Survei } & \text { Demografi } & \text { dan } \\ \text { Kesehatan } & \text { Indonesia } & \text { tahun } & 2017\end{array}$ menunjukkan angka kematian neonatal (AKN) adalah 15 kematian per 1.000 kelahiran hidup, angka kematian bayi (AKB) adalah 24 kematian per 1.000 kelahiran hidup, angka kematian balita (AKBA) adalah 32 kematian per 1.000 kelahiran hidup. Penyebab kematian adalah asfksia $(35,9 \%)$, prematur $(33,1 \%)$, BBLR $(32,4 \%)$ dan sepsis (12\%) (SDKI, 2017).

Profil kesehatan Indonesia di Kota Palembang berdasarkan laporan program anak, jumlah kematian bayi di tahun 2017 sebanyak 29 kasus kematian yang terdiri dari 20 bayi neonatus ( 0 hari - 28 hari) dan 9 bayi (29 hari - 11 bulan) dari 27.876 kelahiran hidup. Penyebab kematian antara lain adalah diare, pneumonia, asfiksia, BBLR, kelainan kongenital, dan lainnya (Profil Kesehatan Kota Palembang, 2017).

Berdasarkan data yang diperoleh dari rekam medik di Rumah Sakit Pusri Palembang, pada tahun 2018 bayi baru lahir berjumlah 1635 bayi, yang mengalami asfiksia neonatorum 116 bayi $(7,09 \%)$ (Rekam Medik Rumah Sakit Pusri Palembang).

Berbagai faktor yang menyebabkan terjadinya asfiksia neonatorum yaitu faktor ibu yang meliputi kehamilan postterm, partus lama, preeklamsia, ketuban pecah dini dan plasenta previa, kemudian faktor tali pusat yang meliputi lilitan tali pusat, prolapsus tali pusat, simpul tali pusat dan tali pusat terlalu pendek, selanjutnya faktor bayi yang meliputi air ketuban bercampur mekonium (berwarna kehijauan), BBLR, bayi prematur, persalinan dengan tindakan (presentasi bokong) (Yuni, 2018).

Penelitian tentang asfiksia neonatorum pernah dilakukan di RSUD Dr $\mathrm{H}$ Abdul Moeloek Bandar Lampung diketahui dari 39 ibu bersalin dengan postterm terdapat 22 bayi baru lahir $(56,4 \%)$ yang mengalami kejadian asfiksia neonatorum, sedangkan dari 314 ibu bersalin yang tidak mengalami kehamilan postterm terdapat 24 bayi baru lahir $(7,6 \%)$ mengalami kejadian asfiksia neonatorum (Lismiati, 2015). 
Berdasarkan uraian diatas, maka penulis tertarik untuk melakukan penelitian yang berjudul "Hubungan Kehamilan Postterm, Partus Lama dan Air Ketuban Bercampur Mekonium dengan Kejadian Asfiksia Neonatorum di Rumah Sakit Pusri Palembang Tahun 2018".

\section{METODE PENELITIAN}

Penelitian ini menggunakan metode survey analitik yaitu suatu penelitian untuk mempelajari suatu dinamika hubungan antara variabel independen dengan variabel dependen, dengan menggunakan pendekatan cross sectional dimana peneliti mempelajari dinamika korelasi antara faktor-faktor resiko dengan efek dengan cara pendekatan, observasi atau pengumpulan data sekaligus dalam waktu yang bersamaan (Notoatmodjo, 2012). Pada penelitian ini, variabel dependen yaitu asfiksia neonatorum dan variabel independen yaitu kehamilan postterm, partus lama, dan air ketuban bercampur mekonium.

Penelitian ini telah dilaksanakan pada bulan April-Mei tahun 2019. Penelitian ini telah dilaksanakan di Rumah Sakit Pusri Palembang. Populasi adalah keseluruhan objek penelitian atau objek yang diteliti. Populasi dalam penelitian ini adalah semua bayi baru lahir yang tercatat di rekam medik

\begin{tabular}{llcc}
\hline No & $\begin{array}{c}\text { Kejadian } \\
\text { Asfiksia } \\
\text { Neonatorum }\end{array}$ & $\begin{array}{c}\text { Frekuensi } \\
(\mathrm{N})\end{array}$ & $\begin{array}{c}\text { Persentasi } \\
(\%)\end{array}$ \\
\hline 1 & Ya & 25 & 26,6 \\
\hline 2 & Tidak & 69 & 73,4 \\
\hline & Jumlah & 94 & 100 \\
\hline
\end{tabular}

Rumah Sakit Pusri Palembang tahun 2018 yang berjumlah 1635 orang (Notoatmodjo, 2012). Sampel yang di gunakan adalah sebagian bayi baru lahir yang tercatat di rekam medik Rumah Sakit Pusri Palembang tahun 2018 (Notoatmodjo, 2012). Pengambilan sampel pada penelitian ini menggunakan systematic random sampling dengan cara membagi jumlah anggota populasi dengan sampel untuk mendapatkan interval dalam penentuan sampel (Notoatmodjo, 2012). Dalam penelitian ini pengumpulan data yang digunakan menggunakan data sekunder. Data sekunder dalam penelitian ini diperoleh dari Rumah Sakit Pusri Palembang yaitu data jumlah kejadian asfiksia neonatorum yang tercatat di Rumah Sakit Pusri Palembang tahun 2018.

Teknik pengolahan data dalam penelitian ini melalui proses editing (pengeditan data), coding (pengkodean data), processing (pemprosesan data), cleaning (pembersihan data). Teknik analisis data disajikan dengan mendistribusikan melalui analisa univariat dan analisa bivariat. Analisis univariat dilakukan terhadap variabel dari hasil penelitian untuk menghasilkan distribusi dan presentase dari tiap variabel. Analisis bivariat bertujuan untuk melihat hubungan antara variabel independen (kehamilan postterm, partus lama, dan air ketuban bercampur mekonium) dan variabel dependen (kejadian asfiksia neonatorum) dengan menggunakan komputerisasi yang akan dianalisis dengan uji statistik chi square $\left(x^{2}\right)$ karena baik variabel independen dan variabel dependen merupakan variabel kategorik, dengan tingkat bermakna $\alpha=$ 0,05, tingkat kepercayaan (Confiden Interval) $95 \%$.

\section{HASIL PENELITIAN}

\section{Analisis Univariat}

$\begin{array}{rr}\text { Tabel 1. Distribusi } & \text { Frekuensi dan } \\ \text { Presentase } & \text { Berdasarkan }\end{array}$

$$
\text { Kejadian Asfiksia Neonatorum }
$$

Dari tabel diatas dapat dilihat dari 94 responden yang mengalami asfiksia neonatorum sebanyak 25 orang $(26,4 \%)$ lebih kecil dibandingkan dengan responden yang tidak mengalami asfiksia neonatorum sebanyak 69 orang $(73,4 \%)$. 
Tabel 2. Distribusi Frekuensi dan Presentase Responden

Kehamilan Postterm

\begin{tabular}{clcc}
\hline No & $\begin{array}{c}\text { Kehamilan } \\
\text { Postterm }\end{array}$ & $\begin{array}{c}\text { Frekuensi } \\
(\mathrm{N})\end{array}$ & $\begin{array}{c}\text { Persentasi } \\
(\%)\end{array}$ \\
\hline 1 & Ya & 22 & 23,4 \\
\hline 2 & Tidak & 72 & 76,6 \\
\hline & Jumlah & 94 & 100 \\
\hline
\end{tabular}

Dari tabel diatas dapat dilihat dari 94 responden yang mengalami kehamilan postterm sebanyak 22 orang $(23,4 \%)$ lebih kecil dibandingkan responden yang tidak mengalami kehamilan postterm sebanyak 72 orang $(76,6 \%)$.

Tabel 3. Distribusi Frekuensi dan Presentase Responden Berdasarkan Air Ketuban Bercampur Mekonium

\begin{tabular}{llcc}
\hline No & $\begin{array}{c}\text { Air Ketuban } \\
\text { Bercampur } \\
\text { Mekonium }\end{array}$ & $\begin{array}{c}\text { Frekuensi } \\
(\mathrm{N})\end{array}$ & $\begin{array}{c}\text { Persentasi } \\
(\%)\end{array}$ \\
\hline 1 & Ya & 19 & 20,2 \\
\hline 2 & Tidak & 75 & 79,8 \\
\hline & Jumlah & 94 & 100 \\
\hline
\end{tabular}

\section{Analisis Bivariat}

Tabel 1. Distribusi Responden Berdasarkan Kehamilan Postterm dengan Kejadian Asfiksia Neonatorum

\begin{tabular}{|c|c|c|c|c|c|c|c|c|c|}
\hline \multirow[t]{3}{*}{ No } & \multirow{3}{*}{$\begin{array}{c}\text { Keham } \\
\text { ilan } \\
\text { postter } \\
m\end{array}$} & \multicolumn{4}{|c|}{$\begin{array}{c}\text { Asfiksia } \\
\text { neonatorum }\end{array}$} & \multicolumn{2}{|c|}{ Total } & \multirow[t]{2}{*}{$p$ value } & \multirow[t]{2}{*}{ OR } \\
\hline & & \multicolumn{2}{|r|}{$\mathrm{Ya}$} & \multicolumn{2}{|c|}{ Tidak } & $\mathrm{N}$ & $\%$ & & \\
\hline & & $\mathrm{n}$ & $\%$ & $\mathrm{n}$ & $\%$ & & & 0,002 & 5,44 \\
\hline 1 & $\mathrm{Ya}$ & 12 & 54,5 & 10 & 45,5 & 22 & 100 & (ber & 6 \\
\hline \multirow[t]{2}{*}{2} & Tidak & 13 & 18,1 & 59 & 81,9 & 72 & 100 & makna) & \\
\hline & Total & 25 & & 69 & & 94 & & & \\
\hline
\end{tabular}

Tabel 2. Distribusi Responden Berdasarkan Partus Lama dengan Kejadian Asfiksia Neonatorum

\begin{tabular}{|c|c|c|c|c|c|c|c|c|c|}
\hline \multirow[t]{3}{*}{ No } & \multirow{3}{*}{$\begin{array}{c}\text { Part } \\
\text { us } \\
\text { lama }\end{array}$} & \multicolumn{4}{|c|}{$\begin{array}{c}\text { Asfiksia } \\
\text { neonatorum }\end{array}$} & \multicolumn{2}{|c|}{ Total } & \multirow[t]{2}{*}{$\begin{array}{c}p \\
\text { value }\end{array}$} & \multirow[t]{2}{*}{ OR } \\
\hline & & \multicolumn{2}{|c|}{$\mathrm{Ya}$} & \multicolumn{2}{|c|}{ Tidak } & \multirow[t]{2}{*}{$\mathrm{N}$} & \multirow[t]{2}{*}{$\%$} & & \\
\hline & & $\mathrm{N}$ & $\%$ & $\mathrm{n}$ & $\%$ & & & \multirow{4}{*}{$\begin{array}{c}0,001 \\
\text { (ber } \\
\text { makn } \\
\text { a) }\end{array}$} & \multirow{4}{*}{$\begin{array}{c}5,71 \\
2\end{array}$} \\
\hline 1 & Ya & 13 & 54,2 & 11 & 45,8 & 24 & 100 & & \\
\hline \multirow[t]{2}{*}{2} & $\begin{array}{c}\text { Tida } \\
\text { k }\end{array}$ & 12 & 17,1 & 58 & 82,9 & 70 & 100 & & \\
\hline & $\mathrm{al}$ & 25 & & 69 & & 94 & & & \\
\hline
\end{tabular}

Tabel 3. Distribusi Responden Berdasarkan Air Ketuban Bercampur Mekonium dengan Kejadian Asfiksia Neonatorum

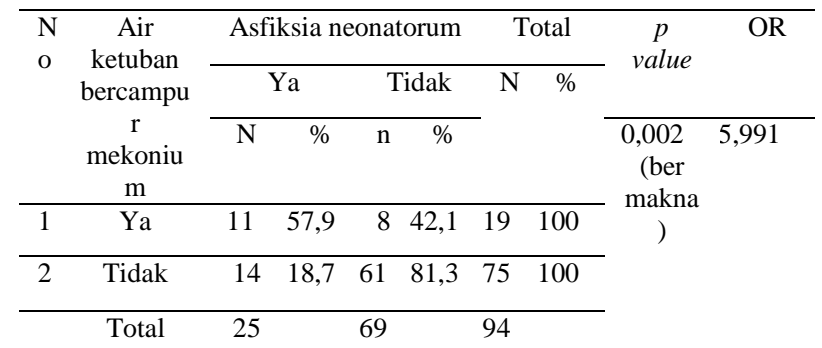

\section{PEMBAHASAN}

Berdasarkan tabel di atas dari 22 responden dengan kehamilan postterm, bayi yang dilahirkan dengan asfiksia neonatorum sebanyak 12 responden $(54,5 \%)$ lebih banyak dibandingkan responden yang tidak mengalami asfiksia neonatorum sebanyak 10 responden $(45,5 \%)$. Sedangkan dari 72 responden yang tidak mengalami kehamilan postterm dengan kejadian asfiksia neonatorum sebanyak 13 responden $(18,1 \%)$ lebih sedikit di bandingkan dengan yang tidak mengalami kejadian asfiksia neonatorum sebanyak 59 responden $(81,9 \%)$ dan hasil uji chi-square dengan tingkat kemaknaan $\alpha=0,05$ diperoleh $\rho$ value $=$ 0,002 .

Dari 24 responden dengan partus lama, bayi yang mengalami asfiksia neonatorum sebanyak 13 responden $(54,2 \%)$ lebih banyak dibandingkan responden yang tidak mengalami asfiksia neonatorum sebanyak 11 responden $(45,8 \%)$. Sedangkan dari 70 responden yang 
tidak mengalami partus lama dengan kejadian asfiksia neonatorum sebanyak 12 responden $(17,1 \%)$ lebih sedikit di bandingkan dengan yang tidak mengalami kejadian asfiksia neonatorum sebanyak 58 responden $(81,9 \%)$ dan dari hasil uji chisquare dengan tingkat kemaknaan $\alpha=0,05$ diperoleh $\rho$ value $=0,001$.

Sedangkan dari 19 responden yang mengalami air ketuban bercampur mekonium, bayi yang dilahirkan mengalami asfiksia neonatorum sebanyak 11 responden $(57,9 \%)$ lebih banyak dibandingkan responden yang tidak mengalami asfiksia neonatorum sebanyak 8 responden $(42,1 \%)$. Sedangkan dari 75 responden yang tidak mengalami air ketuban bercampur mekonium dengan kejadian asfiksia neonatorum sebanyak 14 responden $(18,7 \%)$ lebih sedikit di bandingkan dengan yang tidak mengalami asfiksia neonatorum sebanyak 61 responden $(81,3 \%)$ dan dari hasil uji chi-square dengan tingkat kemaknaan $\alpha=0,05$ diperoleh $\rho$ value $=$ 0,002 .

\section{KESIMPULAN}

1. Ada hubungan yang bermakna kehamilan postterm secara parsial dengan kejadian asfiksia neonatorum di Rumah Sakit Pusri Palembang tahun 2018

2. Ada hubungan yang bermakna partus lama secara parsial dengan kejadian asfiksia neonatorum di Rumah Sakit Pusri Palembang Tahun 2018

3. Ada hubungan yang bermakna air ketuban bercampur mekonium secara parsial dengan kejadian asfiksia neonatorum di Rumah Sakit Pusri Palembang Tahun 2018

4. Ada hubungan kehamilan postterm, partus lama dan air ketuban bercampur mekonium secara simultan dengan kejadian asfiksia neonatorum di Rumah Sakit Pusri Palembang Tahun 2018.

\section{SARAN}

1. Kepada Rumah Sakit Pusri Palembang

Penelitian ini diharapkan dapat memberikan masukan dan informasi bagi penentu kebijakan untuk penatalaksanaan bayi baru lahir dengan asfiksia neonatorum di Rumah Sakit Pusri Palembang

2. Kepada Universitas Kader Bangsa Palembang

Hasil penelitian ini diharapkan dapat digunakan sebagai masukan dan informasi untuk bekal peserta didik dimasa yang akan datang dan dapat menambah bahan di perpustakaan

3. Kepada Peneliti yang Akan Datang Agar penelitian dapat bermakna maka disarankan kepada peneliti selanjutnya untuk meneliti faktor-faktor lain yang berhubungan dengan asfiksia neonatorum dengan desain dan metode penelitian yang berbeda.

\section{UCAPAN TERIMA KASIH}

1. Kepada suamiku Thoyib Hidayat, S.Kom yang selalu memberikan dukungan, semangat, dan do'a yang tiada hentinya.

2. Kepada kedua orang tua ku Ayah Sulaiman, SE dan ibunda ku Agustia Ningsih, S.Pd yang selalu memberikan dukungan, semangat, dan do'a yang tiada hentinya.

3. Dosen pembimbing materi ibu $\mathrm{Hj}$. Herawati, M.Kes dan dosen pembimbing teknis ibu Rizki Amalia, SST, M.Kes ucapan terima kasih yang tak terhingga untuk waktu, ilmu, nasihat dan kesabarannya dalam memberikan bimbingan kepadaku selama ini.

4. Dosen dan staf Universitas Kader Bangsa Palembang prodi diploma IV kebidanan, terima kasih untuk semua do'a dan bimbingannya.

5. Staf Rumah Sakit Pusri Palembang yang telah membantuku dalam melakukan penelitian. 
6. Terimakasih juga ku persembahkan kepada keluarga, sahabat dan temanteman satu angkatan yang senantiasa menjadi penyemangatku.

\section{DAFTAR PUSTAKA}

Saifuddin, Abdul Bahri. 2014. Buku Acuan Nasional Pelayanan Kesehatan Maternal Dan Neonatal. Jakarta: Yayasan Bina Pustaka Sarwono Prawirohardjo.

APN. 2014. Buku Acuan Persalinan Normal. Jakarta: JNPK- KR.

World Health Organization. 2017. Global Health Observatory data repository: Number of deaths by country Birth asphyxia and birth trauma. Diakses 30 Maret 2019. http://apps.who.int/gho/data/view.main. ghe1002015-CH11.

Survey Demografi dan Kesehatan Indonesia Tahun 2017. Jakarta: Kementerian Kesehatan.

Dinkes Kota Palembang. 2017. Profil Kesehatan Kota Palembang Tahun 2017. Diakses 30 Maret 2019. http://dinkes.palembang.go.id.

Rekam Medik Rumah Sakit Pusri Palembang Tahun 2018.

Yuni, F \& Widy ,N. 2018, Asuhan persalinan: konsep persalinan secara komprehensif dalam asuhan kebidanan, Yogyakarta: Pustaka baru Press.

Lismiyati. 2017. Hubungan Kehamilan Postterm Dengan

Kejadian Asfiksia Pada Bayi Baru Lahir Di Rsud Abdul Moeloek. Jurnal Kesehatan "Akbid Wira Buana"Volume 1 N0 1 Edisi April 2017 ISSN:2541-5387.

Notoatmodjo, Soekidjo. 2012. Metodologi Penelitian Kesehatan. Jakarta: Rineka Cipta. 